\title{
Effects of artificial defoliation and simulated insect damage on the growth of Betula pendula saplings
}

Iveta Varnagiryte-Kabašinskiene, Valda Araminiene, Vidas Stakenas

One-year-old silver birch (Betula pendula Roth) saplings were subjected to artificial insect damage and defoliations of varying intensities, and subsequent growth indexes, biomass allocation patterns and photosynthesis were monitored during a 60-day period. Seven treatments were conducted in which the leaves of saplings were perforated with three or six holes per each leaf, and damaged by clipping one-third of each leaf, or they received 25, 50 and $75 \%$ defoliations during a single growing season (from April to August of 2014). Simulated insect damage and artificial defoliation decreased growth. The $75 \%$ defoliation significantly reduced the total dry mass of birch saplings at harvest by $30 \%$, while such reduction did not influence the total productivity. The dry mass of leaves was reduced by $45 \%$ when saplings were defoliated by $75 \%$ compared to not defoliated saplings. Moreover, the total production of leaves significantly increased in the $75 \%$ defoliated saplings compared with control saplings. Artificial defoliation increased the relative biomass allocation to foliage, and this was more evident in defoliated than in mechanically insectdamaged saplings. Despite losing 25,50 or $75 \%$ of leaf mass due to clipping, defoliated birch saplings recovered similar dry masses and root/shoot ratios by harvest as the non-defoliated saplings. Perforation and clipping parts of the leaves, as well as the artificial defoliations, caused the regrowth of biomass that did not significantly change compared to healthy silver birch saplings, and this phenomenon could be assessed as equal-compensatory growth.

Keywords: Betula pendula, Artificial Defoliation, Artificial Insect-Damage, Growth Compensation

tial of individual species and damage scenarios. There are two opposite growth responses to defoliation. In the first, the final vegetative biomass of defoliated plants decreases after the removal of biomass, while in the second the defoliated plants partially or fully compensate for the removal of biomass (Belsky 1986, McNaughton 1986, Oesterheld 1992, Eissenstat \& Duncan 1992, Ferraro \& Oesterheld 2002). Meanwhile, root growth decreases or stops post-defoliation (Eissenstat \& Duncan 1992).

With regard to the compensatory hypothesis (Maschinski \& Whitman 1989), over-, under- or equal-compensatory rates could occur under different site and defoliation conditions. For example, Zhao et al. (2008)

Generally, the effect on biomass produc

tion depends on the compensation potenof leaf area. Therefore, the expected implications of insect damage include reductions in height, biomass and growth rates, as well as changes in photosynthetic activity (Schat \& Blossey 2005, Huttunen et al. 2007).

$\square$ Institute of Forestry, Lithuanian Research Centre for Agriculture and Forestry, Liepu str. 1, Girionys, LT-53101, Kaunas district (Lithuania)

@ Iveta Varnagiryte-Kabašinskiene (iveta.kabasinskiene@mi.lt)

Received: Dec 04, 2014 - Accepted: Mar 10, 2015

Citation: Varnagiryte-Kabašinskiene I, Araminiene V, Stakenas V (2015). Effects of artificial defoliation and simulated insect damage on the growth of Betula pendula saplings. iForest 9: 95-100. - doi: 10.3832/ifor1522-008 [online 2015-07-15]

found a greater reduction in the growth of aboveground biomass when an intense clipping of $80 \%$ was applied. Data from several sources have identified cases of partial compensation, especially for insect-damaged trees (Osier \& Lindroth 2004, Jacquet et al. 2012, Landhäusser \& Lieffers 2012). Some studies investigating growth changes under various insect damage scenarios have focused exclusively on birch species (Hoogesteger \& Karlsson 1992, Hjälten et al. 1993, Mutikainen et al. 2000, Anttonen et al. 2002, Huttunen et al. 2013).

It has been demonstrated that the greater ability of birches to exhibit compensatory growth and recover after severe defoliation occurs faster after increasing the nutrient supply (Reich et al. 1993, Mutikainen et al. 2000). Subsequently, Anttonen et al. (2002) reported that nutrient availability was significant only in determining how the total biomass responded to defoliation, and no interaction between defoliation and fertilization was found in the second growing season after the defoliation.

Previous research has indicated that photosynthetic rates increase in damaged leaves, or even in healthy leaves adjacent to damage (Danckwerts 1993, Meyer 1998, Thomson et al. 2003, Stevens et al. 2008).

Numerous studies have attempted to explain the different consequences of defoliation for relative biomass allocation (MC- 
Naughton 1986, Anttonen et al. 2002, Zhao et al. 2008, Stevens et al. 2008). Markkola et al. (2004) showed that the loss of foliage decreases the root-to-shoot ratio, i.e., changes in the partitioning between above- and below-ground biomass occur, as shoot growth is favored at the expense of root growth (Oesterheld 1992).

The present study was designed to investigate the effects of different artificial defoliation and simulated insect-damage regimes on the growth characteristics of silver birch saplings. The first objective of this study was to determine possible changes in dry mass and relative biomass allocation across different compartments of birch saplings. We also conducted a pilot study on foliar gas-exchange, aiming to investigate the effect of simulated insect damage and partial defoliation on the photosynthetic characteristics of the remaining leaves.

\section{Materials and Methods}

\section{Site description}

This research was conducted in southwestern Lithuania ( $\left.54^{\circ} 51^{\prime} \mathrm{N}, 24^{\circ} 03^{\prime} \mathrm{E}\right)$ at the Dubrava Experimental and Training Forest Enterprise. The mean annual temperature in this area was $6.5^{\circ} \mathrm{C}$, ranging from $5.0-13.7{ }^{\circ} \mathrm{C}$ in April, $8.8-17.1^{\circ} \mathrm{C}$ in May, $13.2-16.8^{\circ} \mathrm{C}$ in June, $19.3-22.8^{\circ} \mathrm{C}$ in July and $13.7-22.5^{\circ} \mathrm{C}$ in August. The mean monthly temperature was higher by $1-1.5^{\circ} \mathrm{C}$ (May) to $3-4.5{ }^{\circ} \mathrm{C}$ degrees (July) compared to the standard climatic norm during the vegetation season. The mean annual precipitation was $686 \mathrm{~mm}$, with $21 \mathrm{~mm}$ in April, $84 \mathrm{~mm}$ in May, $57 \mathrm{~mm}$ in June, $71 \mathrm{~mm}$ in July and 112 $\mathrm{mm}$ in August. The mean monthly precipitation was close to the standard climatic norm.

\section{Plant material and study design}

In this study, a pot-cultivated experiment of silver birch (Betula pendula Roth) saplings was conducted. Initially, all experimental material was approximately equal in size, averaging $40.6 \pm 0.14 \mathrm{~cm}$ of height. Before treatment, the growth of birch saplings did not differ among treatments (Kruskal-Wallis ANOVA: $p<0.05$ ).

The soil for planting was prepared by $\mathrm{mi}-$ xing sand and neutralized peat in a 1:5 ratio.

Saplings were planted into individual 3-L plastic pots filled with the mixed substrate. The mean $\mathrm{pH}$ value of the soil in the pots was 5.0. The total nitrogen and potassium contents of the soil were 0.4 and $40 \mathrm{mg} \mathrm{l}^{-1}$, respectively. The soil received no fertilizer. Throughout the experiment, trees were watered as needed. Pots had 16 equidistant perforations at the base to allow excess water to drain.

One-year-old silver birch saplings were planted on April 2, 2014. Each sapling was planted in its own pot and numbered. Artificial defoliation of 25,50 and $75 \%$ and three different types of simulated insect damages, i.e., three and six holes per each leaf, and clipping one-third of each leaf, were conducted on June 17, 2014. No visible injury caused by biotic and abiotic agents was fixed during the experimental period. In total, seven treatments were conducted, including a non-defoliated control. Each treatment had 20 replicates. Potted trees were placed adjacent to each other in rows, the treatments were mixed. The intensities of the defoliation treatments were designed to approximate insect defoliation levels during the active vegetation period in Lithuania. The simulated damages showed the different insect feeding intensity during outbreaks. The artificial defoliation was the basis for the potentially different effects of the remaining parts of the birch saplings.

The defoliation was conducted using scissors, cutting each leaf perpendicular to the midrib near its base. Each leaf was damaged with 3 or 6 non-overlapping holes $\left(0.33 \mathrm{~cm}^{2}\right)$ using a steel hole-punch, or onethird of each leaf was cut using scissors. Defoliation treatments were applied only once, at the beginning of the experiment.

\section{Growth measurements and biomass harvest}

\section{Height measurements}

The individual height of birch saplings before each treatment was measured on April 4, April 24, May 15 and June 4 to calculate the relative growth rates in different periods. The height increment was measured 1,5 and 8 weeks post-defoliation on June 25 , July 25 and August 18 , respectively.

\section{Biomass harvest}

At the end of experiment, aboveground biomass was sampled on August 18 or 8 weeks post-defoliation. For the determination of total dry mass, samples were removed from the following aboveground tree compartments: leaves, living and dead shoots, branches and stems.

The samples were transported to the laboratory in paper bags. The bags were stored in a clean and ventilated room, and left open prior to oven drying. The oven drying took place in the weeks immediately after sampling. The removed biomass from each treatment, as well as the final live biomass, was collected and oven-dried to a constant weight at $60^{\circ} \mathrm{C}$ to determine the accumulated aboveground biomass. Roots were then harvested, rinsed of soil and oven-dried to determine the total belowground biomass.

\section{Post-harvest measurements}

The leaf areas of 3 leaves, taken randomly from each sapling per each treatment, were estimated using a scanner using leaf area analysis software (WinFOLIA 2004a, Regent Instruments Inc., Quebec, Canada). Later, specific leaf area was interpreted as the projected leaf area/leaf dry mass ratio and used for re-calculation of the photo- synthetic rate per square centimeter per treatment. The diameter of air-dried main stems was measured at a $2 \mathrm{~cm}$ distance above the stump base for each individual sapling using an electronic digital caliper. The length of the roots of each sapling was measured from the root base to the bottom, straightening the root before measurement.

\section{Gas-exchange measurements}

The net photosynthetic rate of the remnant leaves was measured with a portable photosynthetic system LCpro-SD (ADC BioScientific Ltd, Hoddesdon, England). Measurements were taken 1 day, 4 weeks and 7 weeks (June 18 to August 4) after the clippings. To avoid strong sunlight and wind, the measurements were conducted between 10:00 AM and 1:00 PM.

For the first measurement, five systematically selected birch saplings were taken from four treatments: the non-defoliated control, the simulated insect damages of three or six holes per leaf, and the clipped third of the leaf. The photosynthetic rate was measured for three leaves from each sapling, yielding 15 leaves per treatment. For the measurements conducted after 4 and 7 weeks, the saplings from all treatments were measured following the same selection scheme. We measured mature, sunlit, naturally undamaged leaves in each treatment.

The chlorophyll $a$ and $b$ contents of the remnant leaves were determined by a spectrophotometric method using ethanol extraction. The leaf sampling was conducted 7 weeks after the treatment (on August 7). We measured leaves sampled from the non-defoliated control, 50\%-defoliated saplings and saplings with 6 holedamaged leaves. From each treatment, nine leaves were sampled from the middle crown. Later, the samples were combined into 3 samples. We calculated total chlorophyll, and chlorophyll $a$ and $b$ concentrations ( $\mathrm{mg} \mathrm{l}^{-1}$ ) based on the following formulas (eqn. 1, eqn. 2, eqn. 3):

$$
\begin{gathered}
\text { Chla }=9.784 \cdot D_{662}-0.990 \cdot D_{664} \\
\text { Chl } b=21.426 \cdot D_{664}-4.650 \cdot D_{662} \\
\text { Chl } a+b=5.134 \cdot D_{662}+20.436 \cdot D_{664}
\end{gathered}
$$

where $D$ is the sample absorbance at 644 $\mathrm{nm}$ wavelength. The chlorophyll content of leaves was expressed in milligrams per gram of fresh weight of leaves as follows (eqn. 4):

$$
A=\frac{C \cdot V}{100 P}
$$

where $A$ is the chlorophyll content of the fresh weight of leaves ( $\left.\mathrm{mg} \mathrm{g}^{-1}\right), C$ is the chlorophyll concentration ( $\left.\mathrm{mg} \mathrm{l}^{-1}\right), V$ is the volume of chlorophyll extract $(\mathrm{ml})$ and $P$ is the weight of plant material (g). 
Calculations and statistical analysis

The total aboveground biomass of each tree was calculated by the summation of the mass of dried shoots, branches and leaves, in grams. The total biomass of each tree was calculated by the summation of the aboveground and belowground biomass, in grams. Leaf, aboveground and total production or cumulative dry mass were calculated by summing the dry mass at harvest plus the leaf mass removed during insect damage and in the defoliation events. Root biomass was expressed in relation to the aboveground biomass, and the root-to-shoot ratio (root/shoot ratio) was calculated. Cumulative leaf dry mass in relation to the root was calculated, and the ratio of leaf production-to-root ratio (leaf production/root ratio) was obtained.

Departure from normal distribution of the variables was tested by Lilliefors and Kolmogorov-Smirnov tests. However, the normality hypothesis was rejected for all observed variables $(\alpha=0.05)$.

The Kruskal-Wallis analysis of variance (ANOVA) test was used to ascertain the significant differences in dry mass between the different treatments ( 7 groups: control, 3 and 6 holes per leaf, clipped onethird of leaf, and 25, 50 and $75 \%$ defoliations). The test was taken as a non-parametric alternative to between-groups oneway ANOVA, as the data were non-normally distributed. Throughout the study, the means are presented with the standard error of the mean $( \pm$ SE). Statistical analyses were conducted using the software STATISTICA 7.0 (StatSoft, Tulsa, OK, USA), and a level of significance of $\alpha=0.05$ was chosen in all cases.

\section{Results}

\section{Growth and biomass allocation}

At the end of the experiment, the largest height increment of $6.0-6.5 \mathrm{~cm}$ was found in the $75 \%$-defoliated saplings and in those with clipped one-third of leaf compared to their height before treatment (Tab. 1). Other treatments did not show any remarkable difference compared to not defo-

Tab. 1 - Height $(\mathrm{cm})$ of B. pendula saplings 1, 5 and 8 weeks after treatment. Values are given as the mean \pm standard error $(S E, n=20)$. Non statistically significant differences between treatments are indicated in all cases at $p<0.05$.

\begin{tabular}{lccc}
\hline \multirow{2}{*}{ Treatment } & \multicolumn{3}{c}{ Time after treatment } \\
\cline { 2 - 4 } & $\mathbf{1}$ week & $\mathbf{5}$ weeks & $\mathbf{8}$ weeks \\
\hline Control & $53.4 \pm 1.0$ & $55.2 \pm 1.2$ & $56.3 \pm 1.3$ \\
3 holes per leaf & $54.5 \pm 1.0$ & $55.8 \pm 1.1$ & $56.4 \pm 1.1$ \\
6 holes per leaf & $55.4 \pm 1.1$ & $57.5 \pm 1.3$ & $58.0 \pm 1.3$ \\
Clipped one-third of leaf & $55.0 \pm 0.9$ & $57.5 \pm 1.1$ & $58.5 \pm 1.1$ \\
25\% defoliation & $52.4 \pm 1.0$ & $53.9 \pm 1.1$ & $54.7 \pm 1.1$ \\
50\% defoliation & $53.8 \pm 0.9$ & $56.0 \pm 0.9$ & $56.5 \pm 0.9$ \\
75\% defoliation & $53.4 \pm 1.0$ & $56.0 \pm 1.3$ & $57.1 \pm 1.3$ \\
\hline
\end{tabular}

\section{liated saplings.}

In all cases, simulated insect damage and defoliation decreased growth (Tab. 2). The $75 \%$ defoliation had a significant impact on the biomass present at harvest. The dry mass of silver birch saplings at harvest was by $30 \%$ lower due to the $75 \%$ defoliation, while, when included leaf lost in defoliation, total productivity was not significantly reduced. At harvest, the dry mass of leaves was by $45 \%$ lower in the $75 \%$ defoliated saplings than non-defoliated control. However, total leaf production was by $21 \%$ higher in the $75 \%$ defoliated saplings than in the control saplings.

Lower defoliation intensities (25 and 50\%) had, to some extent, lower impacts on the total dry mass of defoliated saplings at harvest. The dry mass of saplings was approximately by $20 \%$ lower due to the 25 and $50 \%$ defoliation, while total productivity did not differ from controls. However, the total dry mass of leaves was significantly reduced by $30-33 \%$. At harvest, the total production of leaves was significantly by $22 \%$ higher in the $50 \%$ defoliated saplings compared with the control. This response was similar to that of the $75 \%$-defoliated saplings.

In almost all cases, different intensities of simulated insect damages ( 3 and 6 holes, $1 / 3$ clipped leaf) did not significantly affect the dry mass of damaged saplings. For example, the total leaf dry mass of saplings damaged with 6 holes per each leaf was lower by $16 \%$ than that of the control, while the total dry mass at harvest remained similar to that of the controls, with a slight, increasing tendency.

Similar to the response of aboveground dry mass, root dry mass was also significantly reduced by $28 \%$ in the $75 \%$ defoliated saplings. The root dry mass in the other defoliation treatments did not respond significantly. The differences in biomass partitioning enabled artificially insect-damaged and defoliated saplings to recover root/ shoot ratios that were similar to that of the control saplings (Tab. 2). Relative biomass allocation across the compartments of birch saplings at harvest was affected mainly by defoliation treatments as compared with the simulated insect damage (Tab. 2, Fig. 1).

Defoliation increased the relative biomass allocation to leaves. In comparison with the control saplings, $75 \%$-defoliated saplings allocated a greater proportion of their biomass to leaf production: the ratio of total leaf production relative to root production was 0.72 in the $75 \%$-defoliated saplings and 0.41 in the controls (Tab. 2). The 25- and 50\%-defoliated saplings allocated a lower proportion of mass to leaf production than the $75 \%$-defoliated saplings (Tab. 2). However, the ratio of total leaf production to root production was higher than in the controls (0.41), i.e., it was 0.49 and 0.60 in the 25 - and $50 \%$-defoliated saplings, respectively. Simulated insect damage did not affect the leaf production-to-roots ratio.

Tab. 2 - Dry mass (g) of leaves, shoots, stems and roots of B. pendula saplings at harvest. Values are given as the mean \pm SE ( $n=20)$. Different letters within a row indicate statistically significant differences in dry mass between treatments $(p<0.05)$. (1): Leaf production include leaf lost in defoliation (cumulative dry mass); (2): total production value was obtained by summing dry mass at harvest plus leaf mass removed in defoliation events; (3): Gram roots / (gram stems + gram shoots + gram leaf); (4): Gram leaf production / gram roots.

\begin{tabular}{|c|c|c|c|c|c|c|c|}
\hline \multirow[b]{2}{*}{ Variable } & \multirow[b]{2}{*}{ Control } & \multicolumn{3}{|c|}{ Simulated insect damage } & \multicolumn{3}{|c|}{ Artificial defoliation } \\
\hline & & $\begin{array}{l}3 \text { holes } \\
\text { per leaf }\end{array}$ & $\begin{array}{l}6 \text { holes } \\
\text { per leaf }\end{array}$ & $\begin{array}{c}\text { Clipped } 1 / 3 \\
\text { of leaf }\end{array}$ & $25 \%$ & $50 \%$ & $75 \%$ \\
\hline Leaf mass (g) & $2.19 \pm 0.16^{\mathrm{d}}$ & $1.97 \pm 0.12^{\mathrm{bcd}}$ & $1.84 \pm 0.11^{\mathrm{bcd}}$ & $1.91 \pm 0.12^{\mathrm{bcd}}$ & $1.46 \pm 0.10^{\mathrm{abc}}$ & $1.53 \pm 0.12^{\mathrm{ab}}$ & $1.21 \pm 0.10^{\mathrm{a}}$ \\
\hline Leaf production $(\mathrm{g})^{1}$ & $2.19 \pm 0.16^{\mathrm{ab}}$ & $2.19 \pm 0.12^{\mathrm{ab}}$ & $2.27 \pm 0.11^{\mathrm{ab}}$ & $2.48 \pm 0.12^{\mathrm{ab}}$ & $1.98 \pm 0.10^{\mathrm{a}}$ & $2.67 \pm 0.12^{b}$ & $2.66 \pm 0.10^{\mathrm{b}}$ \\
\hline Shoot mass (g) & $0.44 \pm 0.05^{\mathrm{a}}$ & $0.43 \pm 0.05^{\mathrm{a}}$ & $0.45 \pm 0.05^{\mathrm{a}}$ & $0.41 \pm 0.03^{\mathrm{a}}$ & $0.40 \pm 0.04^{a}$ & $0.37 \pm 0.04^{\mathrm{a}}$ & $0.35 \pm 0.03^{\mathrm{a}}$ \\
\hline Stem mass $(g)$ & $4.06+0.23^{\mathrm{b}}$ & $3.95+0.21^{\mathrm{b}}$ & $3.79 \pm 0.22^{\mathrm{ab}}$ & $3.60+0.13^{\mathrm{ab}}$ & $3.44 \pm 0.16^{\mathrm{ab}}$ & $3.53+0.15^{\mathrm{ab}}$ & $3.09+0.14^{\mathrm{a}}$ \\
\hline Root mass (g) & $5.27 \pm 0.28^{b}$ & $4.88 \pm 0.29^{\mathrm{ab}}$ & $4.74 \pm 0.31^{\mathrm{ab}}$ & $4.75 \pm 0.25^{\mathrm{ab}}$ & $4.13 \pm 0.25^{\mathrm{ab}}$ & $4.54 \pm 0.26^{\mathrm{ab}}$ & $3.81 \pm 0.19^{\mathrm{a}}$ \\
\hline Total mass (g) & $11.96 \pm 0.68^{\mathrm{b}}$ & $11.24 \pm 0.63^{b}$ & $10.82 \pm 0.63^{\mathrm{ab}}$ & $10.66 \pm 0.48^{\mathrm{ab}}$ & $9.42 \pm 0.52^{\mathrm{ab}}$ & $9.97 \pm 0.52^{\mathrm{ab}}$ & $8.45 \pm 0.41^{\mathrm{a}}$ \\
\hline Total production $(\mathrm{g})^{2}$ & $11.96 \pm 0.68^{\mathrm{a}}$ & $11.45 \pm 0.63^{\mathrm{a}}$ & $11.25 \pm 0.63^{\mathrm{a}}$ & $11.24 \pm 0.48^{\mathrm{a}}$ & $9.94 \pm 0.52^{\mathrm{a}}$ & $11.11 \pm 0.52^{\mathrm{a}}$ & $9.91 \pm 0.41^{\mathrm{a}}$ \\
\hline Root/shoot ratio 3 & $0.80 \pm 0.02^{\mathrm{a}}$ & $0.77 \pm 0.02^{\mathrm{a}}$ & $0.79 \pm 0.03^{\mathrm{a}}$ & $0.81 \pm 0.03^{\mathrm{a}}$ & $0.78 \pm 0.02^{\mathrm{a}}$ & $0.84 \pm 0.03^{\mathrm{a}}$ & $0.83 \pm 0.03^{\mathrm{a}}$ \\
\hline Leaf production/ root ratio ${ }^{4}$ & $0.41 \pm 0.02^{\mathrm{a}}$ & $0.46 \pm 0.02^{\mathrm{ab}}$ & $0.49 \pm 0.02^{\mathrm{abc}}$ & $0.53 \pm 0.02^{\mathrm{bc}}$ & $0.49 \pm 0.01^{\mathrm{abc}}$ & $0.60 \pm 0.02^{\text {cd }}$ & $0.72 \pm 0.03^{d}$ \\
\hline
\end{tabular}




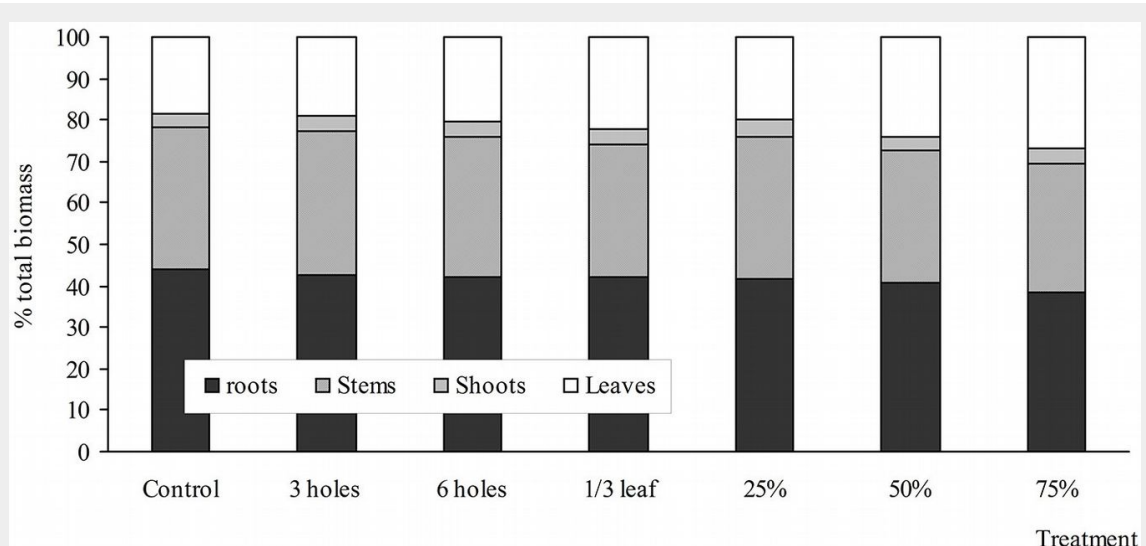

Fig. 1 - Biomass allocation to stem, leaves, and branches of B. pendula saplings in the different treatments of simulated insect damage and artificial defoliation 60 days after treatment.

Tab. 3 - Photosynthetic rate $\left(\mu \mathrm{mol} \mathrm{m} \mathrm{m}^{-2}\right)$ of the remnant leaves of $B$. pendula saplings one day, 4 and 7 weeks after treatment. Values are given as the mean $\pm \operatorname{SE}(n=15)$. Different letters indicate statistically significant differences in dry mass between treatments $(p<0.05)$.

\begin{tabular}{lcc}
\hline \multirow{2}{*}{ Treatment } & \multicolumn{2}{c}{ Time after treatment } \\
\cline { 2 - 3 } & 4 weeks & $\mathbf{7}$ weeks \\
\hline Control & $1.22 \pm 0.20$ & $1.80 \pm 0.25^{\mathrm{ab}}$ \\
3 holes per leaf & $0.98 \pm 0.13$ & $1.28 \pm 0.23^{\mathrm{a}}$ \\
6 holes per leaf & $1.58 \pm 0.49$ & $2.05 \pm 0.36^{\mathrm{ab}}$ \\
Clipped one-third of leaf & $0.72 \pm 0.13$ & $2.99 \pm 0.30^{\mathrm{b}}$ \\
25\% defoliation & $1.19 \pm 0.16$ & $1.07 \pm 0.19^{\mathrm{a}}$ \\
$50 \%$ defoliation & $1.81 \pm 0.48$ & $1.41 \pm 0.16^{\mathrm{a}}$ \\
$75 \%$ defoliation & $1.24 \pm 0.16$ & $1.83 \pm 0.16^{\mathrm{ab}}$ \\
\hline
\end{tabular}

\section{Effects on photosynthetic indexes}

Leaf photosynthesis responded inconsis tently to different defoliation regimes or damage levels (Tab. 3). In June, one day after treatment, the photosynthetic rate was lower in damaged than control saplings (data not shown). A significant increase in the photosynthetic rate in response to clipping one-third of each leaf was observed 7 weeks post-treatment. In contrast, reduced photosynthetic rates were obtained after weak artificial insectdamage (leaves damaged with 3 holes) and the moderate 25 and $50 \%$ defoliation regimes, although these differences were not significant.

The pilot study of foliar chlorophyll content showed that simulated insect-damage with 6 holes per each leaf and 50\% defoliation significantly ( $p=0.007-0.02)$ decreased the content of chlorophyll $a$ from $2.41 \pm$ 0.15 in the controls to $1.57 \pm 0.13$ and $1.63 \pm$ $0.11 \mathrm{mg} \mathrm{g}^{-1}$, respectively. The chlorophyll $b$ content decreased by $17 \%$ and total chlorophyll - by 30\% in the saplings damaged with compared with controls 7 weeks after treatment (data not shown).

\section{Effects on some indexes of leaves, stem and roots}

The $75 \%$ defoliation significantly decreased the diameter of the main stem compared with that of the control ( $p=0.007$ Tab. 4). The other defoliation regimes, as well as the simulated insect damages, had 6 holes per each leaf and 50\% defoliation

Tab. 4 - Leaf area $\left(\mathrm{cm}^{2}\right)$, diameter of main-stem $(\mathrm{mm})$ and length of main-root $(\mathrm{cm})$ of B. pendula saplings 8 weeks after treatment. Values are given as the mean \pm SE $(n=20)$. Different letters indicate statistically significant differences in dry mass between treatments $(p<0.05)$.

\begin{tabular}{lccc}
\hline Treatment & $\begin{array}{c}\text { Leaf area } \\
\left(\mathbf{c m}^{2}\right)\end{array}$ & $\begin{array}{c}\text { Diameter of } \\
\text { main-stem }(\mathbf{m m})\end{array}$ & $\begin{array}{c}\text { Length of } \\
\text { main-root }(\mathbf{c m})\end{array}$ \\
\hline Control & $8.75 \pm 0.35^{\mathrm{b}}$ & $5.66 \pm 0.13^{\mathrm{b}}$ & $43.55 \pm 2.20^{\mathrm{b}}$ \\
3 holes per leaf & $9.13 \pm 0.30^{\mathrm{b}}$ & $5.65 \pm 0.15^{\mathrm{b}}$ & $43.75 \pm 1.94^{\mathrm{b}}$ \\
6 holes per leaf & $8.02 \pm 0.35^{\mathrm{b}}$ & $5.48 \pm 0.15^{\mathrm{b}}$ & $38.40 \pm 1.34^{\mathrm{a}}$ \\
Clipped one-third of leaf & $6.90 \pm 0.30^{\mathrm{a}}$ & $5.31 \pm 0.10^{\mathrm{b}}$ & $39.15 \pm 1.68^{\mathrm{ab}}$ \\
25\% defoliation & $8.83 \pm 0.30^{\mathrm{b}}$ & $5.44 \pm 0.12^{\mathrm{b}}$ & $37.20 \pm 1.68^{\mathrm{a}}$ \\
50\% defoliation & $8.02 \pm 0.35^{\mathrm{b}}$ & $5.37 \pm 0.10^{\mathrm{b}}$ & $37.26 \pm 1.06^{\mathrm{a}}$ \\
75\% defoliation & $7.95 \pm 0.40^{\mathrm{b}}$ & $4.99 \pm 0.10^{\mathrm{a}}$ & $39.45 \pm 1.66^{\mathrm{ab}}$ \\
\hline
\end{tabular}

no significant effect on the diameter of the main stem.

At the final harvest, the clipped leaves treatment significantly decreased the leaf area by $20 \%$ (Tab. 4). Decreases of $8-9 \%$ were found after the 6 holes per leaf and 50 and $75 \%$ defoliation treatments.

The results obtained from the root analysis showed that the 25 and $50 \%$ defoliations caused the highest reductions, up to $15 \%$, in the length of the main root. About a 10-12\% significant reduction was found in the 6 holes per leaf treatments.

\section{Discussion}

This study was set out with the aim of assessing the effects of different simulated insect damage levels and defoliation regimes on the growth characteristics of silver birch saplings. Our results confirmed that defoliated plants partially or fully compensate for the removal of biomass (Belsky 1986, Oesterheld \& McNaughton 1988, Oesterheld 1992, Ferraro \& Oesterheld 2002). The main growth indexes of defoliated saplings grown under the same nutrient conditions most often showed the compensatory response in the case of total productivity. However, no data showed that the stimulation of productivity resulted in overcompensation, as demonstrated for example by Oesterheld \& McNaughton (1991).

Saplings were able to tolerate the defoliation of all studied regimes and all damage levels with slight effects on height growth. This study was unable to demonstrate a reduction in height growth in response to the 50 and $75 \%$ defoliation treatments, as found by Augner et al. (1997).

In our study, a single $75 \%$ defoliation event had a significant effect on leaf and stem biomass. All treatments non-significantly decreased the total aboveground and belowground biomass at harvest, as well as the masses of leaves and stems compared with controls. These changes were similar to those obtained by McGraw et al. (1990). Nevertheless, the cumulative dry mass of birch leaves increased in response to the 50 and $75 \%$ defoliation intensities.

Despite losing a considerable part of leaf mass due to clipping, 25-, 50- or 75\%-defoliated birch saplings recovered similar dry masses and root/shoot ratios by harvest as the control saplings. This finding supports previous research by Oesterheld \& McNaughton (1988), who reported that the root/ shoot ratio recovered by the end of the experiment after a previously drastic increase by clipping.

Other studies confirm that 50\%-defoliated plants recovered similarly to non-defoliated plants, and those defoliated by $25 \%$ even overcompensated their biomass compared with controls (Reich et al. 1993). In our case, saplings that lost $50 \%$ of their foliage increased their growth rate by $40 \%$ to achieve a biomass that was similar to that of the controls. Similarly, the growth rate of saplings that were damaged by the 
$75 \%$ defoliation was even greater, i.e., their relative growth rate was 2 -fold higher than that of controls, which enabled their biomass to reach a level that was similar to that of the controls. Surveys, such as that conducted by Reich et al. (1993), have shown that plants defoliated by $75 \%$ were only able to partially compensate biomass growth and recover. Our findings are not fully consistent with these results, as we found full compensation, or even a slight overcompensation, in the case of leaf productivity.

The leaf areas of defoliated saplings did not differ from that of the control; therefore, we could assume that their recovery was obvious in terms of leaf area, which was much changed during the single artificial defoliation and simulated insect damage events. We confirm the findings that specific leaf area was unaffected by defoliation treatment (Reich et al. 1993), although the leaf weight ratio decreased under the $25-75 \%$ defoliation events.

Allocation refers to the amount of biomass apportioned to each above-ground compartment (leaves, shoots and stems) and roots over the duration of the experiment or 8 weeks post-defoliation. Moderate and severe defoliation regimes correlated with greater biomass allocations to leaves. The findings of Reich at al. (1993), who examined biomass partitioning in red pine, showed that biomass shifted towards foliage. Changes in allocation that resulted in a higher production of new leaf area were also obtained by Oesterheld \& McNaughton (1988). Otherwise, our findings are not comparable with those of Honkanen et al. (1994), who found a biomass allocation to stems.

Other existing studies also show a similar tendency, but a higher-nutrient level was given as a specific condition (Stevens et al. 2008). Fertilization increased the growth of silver birch saplings at all defoliation levels, demonstrating that nutrient availability limited growth in the experimental field. However, we did not use additional fertilizers, and, therefore, our results differed from those of some other studies (e.g., Maschinski \& Whitman 1989, Reich et al. 1993, Anttonen et al. 2002, Stevens et al. 2008). It could only be assumed that the increased growth compensation was revealed after the additional input of nutrients (Maschinski \& Whitman 1989, Zhao et al. 2008). The same tendency could occur if pot size limits root growth, as stated by Oesterheld (1992).

The current study found significantly increased photosynthetic rate only in the clipped leaf treatment seven weeks postdefoliation. Otherwise, changes in the photosynthetic area per plant were small over a relatively short period of time. Moreover, despite the significant increase in leaf productivity, the severe $75 \%$ defoliation did not cause any changes in the photosynthetic rates compared to the control. However, the moderate defoliation events reduced the photosynthetic rate.

To a certain extent, an atypical response of photosynthesis was observed - it did not increase with increasing defoliation intensity. The reduction of photosynthetic activity after partial leaf removal was presented by Zangerl et al. (1997). Otherwise, Huttunen et al. (2007) discussed that the ability to photosynthesize decreases in low nutrient soils, which, therefore, could have an impact on growth. In our experiment, the soil could be characterized as a nutrient-poor substrate. McGraw et al. (1990) found that defoliation alone did not have a significant effect on photosynthesis, as such effects varied with the watering regime.

In terms of diameter growth, saplings reduced their growth under the highest defoliation intensity at harvest, but did not respond to other treatments. Indeed, such a quick response is quite a good outcome of this experiment compared with some other studies, which found the response only after a longer period (Hoogesteger \& Karlsson 1992).

The artificial holes and defoliation may not exactly repeat the natural insect feeding (Lyytikainen 1994). Some of simulated indexes including the size of the treated area or the amount of removed foliage caused by artificial and natural agents could be similar. However, the plant possibly recognize a sustained damage by feeding insects from the artificial damage which was conducted with own damage strategy and location in the plant only once per vegetation season. A study of different damage types by Hartley \& Lawton (1987) reported that defoliation induced by natural insect herbivory caused stronger responses compared to the artificial damage. However, we have not succeeded to find any published material of similar investigations conducted in naturally growing birch stands. The information regarding natural birch damages induced by insects is available only from the permanent observation plots established in the birch stands and monitored for almost 20 years in Lithuania. Still, it only points that no visible insect damages was registered (unpublished).

Returning to the question posed at the beginning of this study, we assume that the obtained defense strategies of birch trees are significant in determining spatial variation and temporal of this species. This should be important for the determination of competitive abilities following herbivory, especially given the fact that the area of birch stands is currently expanding in $\mathrm{Li}$ thuania, at the same time the frequency of insect outbreaks increases.

\section{Conclusions}

We found that silver birch saplings were able to recover from moderate and severe (75\%) defoliation in one growing season. In the case of leaf production, even growth overcompensation could be observed. Different levels of simulated insect damage, perforations of 3 or 6 holes per leaf, gave weaker responses than the defoliation regimes, and the 6 hole-treatment responded similarly to the $25 \%$ defoliation. The recalculation of the dry masses of different compartments to the total production showed that all saplings recovered 8 weeks post-treatment, regardless of the defoliation intensity.

Our results suggest that different defoliation regimes play a considerable role in determining whether silver birch compensates for defoliation. The discrepancy of our findings in the case of photosynthesis could be attributed to specific meteorological conditions, and these findings need to be replicated. According to the present data, the conclusions must be interpreted with caution, and further studies are necessary to explain whether a short time for recovery after artificial defoliation or simulated insect damage and a limited soil nutrient supply could cause any other specific responses.

\section{Acknowledgments}

The paper presents research findings obtained through the long-term research programme "Sustainable forestry and global changes", implemented by the Lithuanian Research Centre for Agriculture and Forestry.

\section{References}

Anttonen S, Piispanen R, Ovaska J, Mutikainen P, Saranpää P, Vapaavuori E (2002). Effects of defoliation on growth, biomass allocation, and wood properties of Betula pendula clones grown at different nutrient levels. Canadian Journal of Forest Research 32: 498-508. - doi: 10.1139/x01-217

Augner M, Tuomi J, Rousi M (1997). Effects of defoliation on competitive interactions in European white birch. Ecology 78: 2369-2377. - doi: 10.1890/0012-9658(1997)078[2369:EODOCI]2. o.CO;2

Belsky AJ (1986). Does herbivory benefit plants? A review of the evidence. American Naturalist 127: 870-892. - doi: 10.1086/284531

Danckwerts JE (1993). Reserve carbon and photosynthesis: their role in regrowth of Themeda triandra, a widely distributed subtropical graminaceous species. Functional Ecology 7: 634-641. - doi: $10.2307 / 2390141$

Eissenstat D, Duncan LW (1992). Root growth and carbohydrate responses in bearing citrus trees following partial canopy removal. Tree Physiology 10: 245-257. - doi: 10.1093/treephys/ 10.3.245

Ferraro DO, Oesterheld M (2002). Effect of defoliation on grass growth. A quantitative review. Oikos 98: 125-133. - doi: 10.1034/j.1600-0706.20 02.980113.x

Hartley SE, Lawton JH (1987). The effects of different types of damage on chemistry of birch foliage and the responses of birch feeding insects. Oecologia 74: 432-437. - doi: 10.1007/BF 00378941

Hjälten J, Danell K, Ericson L (1993). Effects of simulated herbivory and intraspecific competition on the compensatory ability of birches. 
Ecology 74: 1136-1142. - doi: 10.2307/1940483

Honkanen T, Haukioja E, Suomela J (1994). Effects of simulated defoliation and debudding on needle and shoot growth in Scots pine (Pinus sylvestris): implications of plant source/sink relationships for plant-herbivore studies. Functional Ecology 8: 631-639. - doi: 10.2307/2389 926

Hoogesteger J, Karlsson PS (1992). Effects of defoliation on radial stem growth and photosynthesis in the mountain birch (Betula pubescens ssp. tortuosa). Functional Ecology 6: 317-323. - doi: 10.2307/2389523

Huttunen L, Ayres MP, Niemelä P, Heiska S, Tegelberg R, Rousi M, Kellomäki S (2013). Interactive effects of defoliation and climate change on compensatory growth of silver birch seedlings. Silva Fennica 47 (3): article id 964, pp. 14. doi: 10.14214/sf.964

Huttunen L, Niemelä P, Peltola H, Heiska S, Rousi $M$, Kellomäki S (2007). Is a defoliated silver birch seedling able to overcompensate the growth under changing climate? Environmental and Experimental Botany 60: 227-238. - doi: 10.1016/j.envexpbot.2006.10.010

Jacquet JS, Orazio C, Jactel H (2012). Defoliation by processionary moth significantly reduces tree growth: a quantitative review. Annals of Forest Science 69: 857-866. - doi: 10.1007/s1359 5-012-0209-0

Landhäusser SM, Lieffers VJ (2012). Defoliation increases risk of carbon starvation in root systems of mature aspen. Trees 26: 653-666. - doi: 10.1007/s00468-011-0633-z

Lyytikainen P (1994). Effects of natural and artificial defoliation on sawfly performance and foliar chemistry of Scots pine saplings. Annales Zoologici Fennici 31: 307-318. [online] URL: http://www.jstor.org/stable/23735535

Markkola A, Kuikka K, Rautio P, Härmä E, Roitto
M, Tuomi J (2004). Defoliation increases carbon limitation in ectomycorrhizal symbiosis of Betula pubescens. Oecologia 140: 234-240. - doi: 10.1007/s00442-004-1587-2

Maschinski J, Whitman TG (1989). The continuum of plant responses to herbivory: the influence of plant association, nutrient availability, and timing. American Naturalist 134: 1-19. - doi: 10.1086/284962

McGraw JB, Gottschalk KW, Vaver MC, Chester $A L$ (1990). Interactive effects of resource availabilities and defoliation on photosynthesis, growth, and mortality of red oak seedlings. Tree Physiology 7: 247-254. - doi: 10.1093/treephys/7.1-2-3-4.247

MCNaughton SJ (1986). On plant and herbivores. American Naturalist 128: 765-770. - doi: 10.1086/ 284602

Meyer GA (1998). Mechanisms promoting recovery from defoliation in goldenrod (Solidago altissima). Canadian Journal of Botany 76: 450459. - doi: 10.1139/b98-004

Mutikainen $P$, Walls $M$, Ovaska J, Keinänen $M$, Julkunen-Tiitto R, Vapaavuori E (2000). Herbivore resistance in Betula pendula: effect of fertilization, defoliation and plant genotype. Ecology 81: 49-65. - doi: 10.1890/0012-9658(2000) 081[0049:HRIBPE]2.0.CO;2

Oesterheld M (1992). Effect of defoliation intensity on aboveground and belowground relative growth rates. Oecologia 92: 313-316. - doi: 10.1007/BFo0317456

Oesterheld M, McNaughton SJ (1988). Intraspecific variation in the response of Themeda triandra to defoliation. The effect of time of recovery and growth rates on compensatory growth. Oecologia 77: 181-186. - doi: 10.1007/BFoo3 79184

Oesterheld M, McNaughton SJ (1991). Effect of stress and time for recovery on the amount of compensatory growth after grazing. Oecologia 85: 305-313. - doi: 10.1007/BF00320604

Osier TL, Lindroth RL (2004). Long-term effects of defoliation on quaking aspen in relation to genotype and nutrient availability: plant growth, phytochemistry and insect performance. Oecologia 139: 55-65. - doi: 10.1007/soo442003-1481-3

Reich PB, Walters MB, Krause SC, Vanderklein DW, Raffa KF, Tabone T (1993). Growth, nutrition and gas exchange of Pinus resinosa following artificial defoliation. Trees 7: 67-77. - doi: 10.1007/BFo0225472

Schat M, Blossey B (2005). Influence of natural and simulated leaf beetle herbivory on biomass allocation and plant architecture of purple loosestrife (Lythrum salicaria L.). Environmental Entomology 34 (4): 906-914. - doi: 10.1603/004 6-225X-34.4.906

Stevens MT, Kruger EL, Lindroth RL (2008). Variation in tolerance to herbivory is mediated by differences in biomass allocation in aspen. Functional Ecology 22: 40-47. - doi: 10.1111/j.136 5-2435.2007.01356.x

Thomson VP, Cunningham SA, Ball MC, Nicotra $A B$ (2003). Compensation for herbivory by Cucumis sativus through increased photosynthetic capacity and efficiency. Oecologia 134: 167-175. - doi: 10.1007/so0442-002-1102-6

Zangerl AR, Arntz AM, Berenbaum MR (1997). Physiological price of an induced chemical defence: photosynthesis, respiration, biosynthesis, and growth. Oecologia 109: 433-441. doi: $10.1007 /$ s004420050103

Zhao W, Chen SP, Lin GH (2008). Compensatory growth responses to clipping defoliation in Leymus chinensis (Poaceae) under nutrient addition and water deficiency conditions. Plant Ecology 196: 85-99. - doi: 10.1007/s11258-007-9336-3 